\title{
Toxicity Effects of Microplastics Individually and in Combination the Fish Pathogen Yersinia Ruckeri on the Rainbow Trout (Oncorhynchus Mykiss)
}

Elham Alsadat Banihashemi

Shiraz University School of Veterinary Medicine

\section{Siyavash Soltanian}

Shiraz University School of Veterinary Medicine

Amin Gholamhosseini ( $\triangle$ Amingholamhosseini@shirazu.ac.ir)

Shiraz University School of Veterinary Medicine https://orcid.org/0000-0002-0264-1376

Mahdi Banaee

Behbahan Khatam Alanbia University of Technology

\section{Research Article}

Keywords: Yersinia ruckeri, Microplastic, Blood biochemical parameters, Oxidative stree, Rainbow trout

Posted Date: June 9th, 2021

DOI: https://doi.org/10.21203/rs.3.rs-481553/v1

License: (c) (i) This work is licensed under a Creative Commons Attribution 4.0 International License. Read Full License 


\section{Abstract}

Exposure to xenobiotics such as Yersinia ruckeri can significantly affect bacterial infections in fish. Microplastics (MPs) may predispose fish to infection and act as carriers in pathogen transmission. Therefore, this study is designed to evaluate MPs' effect on damage caused by exposure to Y. ruckeri in rainbow trout. In this study, blood biochemical parameters and hepatic oxidative biomarkers as clinical signs were measured in the fish co-exposed to Y. ruckeri (5 and 10\% LD50) and MPs (500 and 1000 mg Kg-1) for 30 days. There were no significant changes in the creatinine, triglyceride, cholesterol levels, and glutamic-pyruvic transaminase activity in the blood of fish infected with $Y$. ruckeri. In contrast, exposure to MPs had a significant effect on most clinical parameters. The total protein, albumin, globulin, total immunoglobulins, Highdensity lipoprotein, low-density lipoprotein, cholesterol levels, and y-glutamyltransferase activity decreased, whereas glucose, triglyceride, and creatinine levels, and glutamic-oxaloacetic transaminase, glutamic-pyruvic transaminase, alkaline phosphatase, and lactate dehydrogenase activities increased in the plasma of fish after co-exposure to MPs and Y. ruckeri. Dietary MPs combined with a bacterial challenge decreased catalase activities, glutathione peroxidase, and total antioxidant levels. However, the superoxide dismutase activity and malondialdehyde contents in the hepatocytes increased in the hepatocyte of fish co-exposed to MPs and Y. ruckeri. In conclusion, this study showed that fish exposure to MPs and simultaneous challenge with $Y$. ruckeri could have a synergistic effect on clinical parameters.

\section{Introduction}

Microplastics (MPs) are known as a newfound and unique pollutant in aquatic ecosystems (Kim, et al., 2021). Along with the increase in plastic products' global production, the amount of garbage and plastic waste in the environment has also esclated (Iheanacho, et al., 2020; Zhang, et al., 2021). Destruction of plastic debris under the influence of UV, physicochemical changes in the environment, and physical processes have caused most plastic compounds to become MPs and enter aquatic ecosystems through surface runoff (Frias \& Roisin Nash, 2019). MPs may enter the fish body through the food chain or absorption by the gills. MPs accumulate in aquatic animals are transported through cells and spread throughout the body through the circulatory system or lymphatic (Wang, et al., 2020; Kim, et al., 2021). MPs often get into the digestive system but can also be transmitted to the liver or other vital organs (Jovanović, 2017). Therefore, the accumulation of MPs in fish's vital tissues can have toxic effects on growth and development, immune system function, oxidative stress, metabolism and energy budgeting, and various biomarkers (Qiao, et al., 2019a; Qiao, et al., 2019b; Bhagat, et al., 2020).

Prolonged exposure to MPs can lead to an inflammatory response in the gut, leading to metabolic disorders and diseases caused by imbalance and damage to the microbial flora of fish intestines (Kang, et al., 2021). Studies show that MPs in aquatic ecosystems can have detrimental effects on aquatic health (Brandts, et al., 2018; Ding, et al., 2018). Exposure of aquatic organisms to MPs can lead to oxidative stress, suppression of the immune system, changes in blood biochemical parameters, histopathological damage, and gene expression changes (Chen, et al., 2020; Pannetier, et al., 2020; Ding, et al., 2020; Banaee \& Shakeri, 2021).

Besides contaminating the aquatic ecosystems, MPs have a high potential for transporting environmental and biological pollutants. Various researchers have studied the MPs' synergistic effect on increasing the toxicity of heavy metals, pesticides, aromatic petroleum hydrocarbons, etc (Nematdoost Haghi \& Banaee, 2017; Banaee, et al., 2019; Kim, et al., 2021). These studies show that MPs can have a significant effect on the bioavailability of environmental pollutants.

Although MPs' effect on the pathogenicity of pathogens has not been studied extensively, there is a hypothesis that exposure of to MPs may suppress the immune system of fish and predispose them to pathogens.

Yersinia ruckeri is an opportunistic pathogenic gram-negative bacterium known to cause enteric redmouth disease. The spread of this bacterium among different commercial fish species can cause significant damage to the aquaculture 
industry. Y. ruckeri has been isolated from various species of fish in many parts of the world. Y. ruckeri is transmitted to fish via water, food, sediments, and aquatic animals. The Yersinia's infection is often transmitted through the faecal-oral route.

Y. ruckeri is an invasive microorganism that can induce infection via tissue destruction. The pathogen passes into the digestive system through contaminated feed and penetrates the intestine's epithelial cells. Y. ruckeri's infection may lead to mucosal ulcers and necrotic lesions in the digestive system of fish. The enterotoxin synthesised by $Y$. ruckeri may play a significant role in causing disease. After challenging fish with bacteria, Y. ruckeri can enter fish blood through gill lamella. The infection affects the intestine, liver, spleen, heart, and brain within 30 minutes to 3 days. Moreover, the bacteria can be detected in these tissues even up to 21 days after the initial challenge (Kumar, et al., 2015).

Since environmental conditions play a crucial role in the prevalence of opportunistic pathogens, the question is whether MPs can predispose fish to yersiniosis. Therefore, assessing the health of fish co-exposed to MPs and $Y$. ruckeri may help answer this question. Blood biochemical parameters are a good indicator for assessing the health of organs involved with pathogens and xenobiotics. Oxidative stress biomarkers are also an indicator of the cellular antioxidant defense system's power against free radicals due to xenobiotics and biological toxins' metabolism. Thus, this study was designed to study fish health based on changes in blood biochemical parameters and oxidative stress biomarkers. Rainbow trout is one of the commercial and farmed species in Iran that is very susceptible to Yersinia infection. In this study, the rainbow trout were used to investigate the clinical signs of the $Y$. ruckeri pathogenesis when facing MPs.

\section{Materials And Methods}

\subsection{Chemical materials}

High-density polyethylene (PE100) powder (<0.2 mm) was purchased from Eshragh Trading Co., Iran. All diagnostic kits used to measure biochemical parameters and antioxidant enzymes were obtained from Pars Azmun Co., and BiorexFars Co., Iran.

\subsection{Fish}

Juvenile rainbow trout were purchased from a private farm and transferred to the Aquatic Animal Health Division (School of Veterinary Medicine, Shiraz University, Iran). The fish were adapted to laboratory conditions (temperature: $15 \pm 2{ }^{\circ} \mathrm{C}$, photoperiod cycle: 14 light/8 dark, dissolved oxygen: $8.1 \pm 0.7 \mathrm{mg} \mathrm{L}^{-1}, \mathrm{pH}: 7.3 \pm 0.4$, electrical conductivity: $693.83 \pm 76 \mu \mathrm{S}$ $\mathrm{cm}^{-1}$, salinity: $0.3 \pm 0.02 \mathrm{~g} \mathrm{~L}^{-1}$ ) for two weeks. The School of Veterinary Medicine's ethical committee confirmed this study's proposal and all the experimental procedures.

\subsection{The median lethal dose $\left(L D_{50}\right)$ of Yersinia ruckeri for rainbow trout}

The Yersinia ruckeri (PTCC No: 1888) was cultured in Trypticase Soy Agar with $5 \%$ defibrinated sheep blood at $25^{\circ} \mathrm{C}$ for 48 h. Next, bacteria were washed twice using sterile phosphate-buffered saline (PBS). The bacterial concentration was adjusted to $10^{10} \mathrm{CFU} \mathrm{ml}{ }^{-1}$ using pour plate count method.

Rainbow trout were randomly distributed into eighteen tanks (9 trial groups in two replicates). Each tank contained fifteen fish. Eight serial dilutions of $Y$. ruckeri suspension $\left(10^{3}\right.$ to $10^{10}$ cells $\left.\mathrm{ml}^{-1}\right)$, were added to each tank $(10 \mathrm{~L})$ for one hour. The fish in the control group were maintained in clean water. Clinical signs and the mortality rate was recorded following the challenge with bacteria for 7 days. During the $\mathrm{LD}_{50}$ experiment, water was aerated and had the same conditions as the acclimation period. The dead fish were immediately removed from the tanks. Mortality due to bacterial infection was confirmed after sampling and bacterial culture in vitro. 7 days $L D_{50}$ (lethal dose affecting 50 percent of a population of animals) was determined by probit analysis. 


\subsection{The Experimental challenge trials}

Two hundred and seventy rainbow trout $(15 \pm 2.5 \mathrm{~g})$ were randomly distributed in twenty-seven fiberglass tanks $(100 \mathrm{~L})$ into

nine separate experimental groups that included group I or control group (without MPs and Y. ruckeri), group II (5\% LD50 of Y. ruckeri), group III (10\% LD50 of Y. ruckeri), group IV (500 mg Kg-1 of MPs), group V (1000 mg Kg-1 of MPs), group VI (5\% LD50 of Y. ruckeri \& $500 \mathrm{mg} \mathrm{Kg}^{-1}$ of MPs), group VII (5\% LD50 of Y. ruckeri \& $1000 \mathrm{mg} \mathrm{Kg}^{-1}$ of MPs), group VIII (10\% LD50 of $Y$. ruckeri \& $500 \mathrm{mg} \mathrm{Kg}^{-1}$ of MPs), and group IX (10\% LD50 of Y. ruckeri \& $1000 \mathrm{mg} \mathrm{Kg}^{-1}$ of MPs) in triplicate following completely randomized design (CRD). Fish were continuously exposed to the MPs for 30 days and challenged with $Y$. ruckeri for one hour on the $1^{\text {st }}, 8^{\text {th }}, 15^{\text {th }}$ and $22^{\text {nd }}$ day of the experiment. Every $24 \mathrm{~h}$ the water was renewed $(100 \%)$ and fresh suspension of MPs were prepared and added to water to maintain the nominal dose. In the experimental periods, rainbow trout were fed two times daily with commercial feed. One day before sampling, fish feeding was stopped. At the end of the challenge period, the fish were anaesthetized using clove powder (150 mg L-1). The blood was sampled from the venous stem vein using a $2.5 \mathrm{~mL}$ syringe impregnated with an anticoagulant. The blood samples were centrifuged (6000 $\mathrm{g}$, at $4^{\circ} \mathrm{C}$ for $15 \mathrm{~min}$ ), and plasma fractions were collected and stored at $-25^{\circ} \mathrm{C}$ until the biochemical analyses.

After the sacrifice, the fish were dissected, then the liver was quickly dissected and homogenized on ice in $100 \mathrm{mM}$ cold potassium phosphate buffer (Sigma-Aldrich, Germany) pH 7.0, with 2 mM EDTA (Riedel-Haën, Germany). Tissue homogenates were centrifuged at $12,000 \mathrm{~g}$-force for 15 minutes at $4{ }^{\circ} \mathrm{C}$ and the supernatants were collected and maintained at $-80^{\circ} \mathrm{C}$ until further analysis.

\subsection{Blood biochemical analysis}

Glutamic-oxaloacetic transaminase (SGOT), glutamic-pyruvic transaminase (SGPT), alkaline phosphatase (ALP), $\mathrm{Y}^{-}$ glutamyltransferase (GGT), and lactate dehydrogenase (LDH) activities, glucose, total cholesterol, triglyceride, high density lipoprotein (HDL), low density lipoprotein (LDL), creatinine, total protein and albumin levels in plasma were evaluated based on the standard methods provided in the diagnostic kit protocol. The globulin levels were also computed based on the following formula:

Globulins $=$ Total protein - Albumin

Total immunoglobulin (lg) was estimated using polyethylene glycol solution according to the procedure described by Banaee et al. (Banaee et al. 2019). All blood biochemical parameters were measured utilizing a UV-visible spectrophotometer (Unico, 2100) and standard biochemical reagents obtained from Pars-Azemun Co, Tehran, Iran.

\subsection{Oxidative biomarker analysis}

Superoxide dismutase (SOD) and glutathione peroxidase (GPx) activities in the hepatocytes were assessed using oxidative biomarker kits purchased from the Biorexfars Co., Iran. The total antioxidant capacity was estimated with the ferric reducing ability of plasma (FRAP) technique using TPTZ (2,4,6-Tris(2-pyridyl)-s-triazine) as a substrate (Benzie and Strain, 1996). Per-oxidative damage in the hepatocytes was evaluated in terms of malondialdehyde (MDA) production by the method presented by Placer and others (Placer et al., 1996), using thiobarbituric as substrate acid and monitored at 532 $\mathrm{nm}$. Catalase (CAT) activity was measured spectrophotometrically in tissue homogenates by using a hydrogen peroxide solution (30 mM) as a substrate and monitored at $450 \mathrm{~nm}$ (Góth, 1991).

\subsection{Assessment of synergism and antagonism}

In the present study, the following mathematical models were used to predict the interaction of MPs and $Y$. ruckeri on each other. According to Banaee et al. (2020), the synergism rate is calculated only when the predicted effect is higher than the observed one. 
1. Predicted effect of the endpoints of rainbow trout exposed to either MPs or ruckeri

Predicted effect $=\frac{\text { Y.ruckeri }}{\text { Control }} \times \frac{\text { MPs }}{\text { Control }}$

2. Observed effect of the endpoints of rainbow trout exposed to both ruckeri and MPs

$$
\text { Observed effect }=\frac{\text { Y. ruckeri combined with MPs }}{\text { Control }}
$$

3. The synergism effect

$$
\text { Synergy ratio }=\frac{\text { Predicted effect }}{\text { Observed effect }}
$$

\subsection{Data analysis}

The Shapiro-Wilk test calculated the normality of all data. Then, changes among the different variables of rainbow trout exposed to Y. ruckeri combined with MPs were analyzed using two-way analysis of variance (two-way ANOVA). A Tukey test was used to compare differences in each parameter between control and experimental groups. Statistical analyses of all data were carried out using Graph Pad Prism 8.0.2. A significant difference was assessed at $P<0.05$ levels, and results were shown as Mean \pm Standard deviation.

\section{Results And Discussion}

Clinical signs such as haemorrhage on the body, especially at the base of the fins and anus, bleeding and inflammation in the intestine's distal parts, petechiae bleeding around the jaw and mouth, bleeding or pale gills were observed in the experimentally infected rainbow trout. We were able to isolate $Y$. ruckeri from the intestine, kidney, liver and gill of all recently dead and survied fish. A cumulative mortality rate of $20 \%, 60 \%, 70 \%, 80 \%$, and $100 \%$ was reached in rainbow trout injected with $Y$. ruckeri isolate at doses of $10^{6}, 10^{7}, 10^{8}, 10^{9}$, and $10^{10} \mathrm{CFU} / \mathrm{L}$, respectively and $\mathrm{LD}_{50}$ value for $Y$. ruckeri was estimated to be $1.42 \times 10^{7} \mathrm{CFU} \mathrm{L}^{-1}$.

Although, none of the fish used in the experiment died during co-exposure to MPs and Y. ruckeri, clinical signs of yersiniosis were observed in fish. The pathogenicity of $Y$. ruckeri and fish mortality may be attributed to virulence factors. The most well-known virulence factors are lipopolysaccharides, hemolysin, Yrp1 protease, ruberbactin, and extracellular metalloproteinase (Portnyagina, et al., 2021). Furthermore, Y. ruckeri can damage host cellular membranes through secreting nonspecific pore-forming proteins (porins) (Portnyagina, et al., 2021).

Glucose is an important energy source in fish, especially in the brain, which gets most of its energy from carbohydrates. However, fish is known as a species with low glucose tolerance. Exposure of fish to MPs and Y. ruckeri led to elevated glucose levels (Figure $1 \&$ Table 1). Elevated glucose may be a physiological response to increased energy demand to combat biotoxins and MPs. Bao et al. (2020) showed that the liver's glucose metabolism gene altered after xenobiotic exposure. An increase in blood glucose may also increase the conversion rate of excess glucose to triglycerides and increase its level. Hamed et al. (2019) and Banaee, et al., (2019b) found that exposure to MPs increases the blood glucose of tilapia O. niloticus and C. carpio, respectively (Hamed et al., 2019, Banaee et al., 2019b). Elevated glucose may be related to plasticiser's effect on insulin resistance and glucose metabolism (Carlsson et al., 2018). Damage to pancreatic beta cells can change blood glucose homeostasis (Ropero, et al., 2008). Plasticisers can interfere with the cellular signalling pathway involved in maintaining blood glucose homeostasis (Stojanoska, Milosevic, Milic, \& Abenavoli, 2017, Han, et al., 2019). The highest levels of glucose were observed in the blood of fish exposed to $1000 \mathrm{mg} \mathrm{Kg}^{-1} \mathrm{MPs}$ and 
challenged with 5\% $\mathrm{LD}_{50}$ Y. ruckeri. This result suggest that MPs and $Y$. ruckeri exert a synergistic effect by increasing the glucose levels.

Creatinine is the most critical metabolite produced by the muscles and excreted through the kidneys. The concentration of creatinine in the blood of fish exposed to $1000 \mathrm{mg} \mathrm{Kg}^{-1} \mathrm{MPs}$ increased significantly compared to the control group. However, there was no significant change in creatinine level in fish fed with $500 \mathrm{mg} \mathrm{Kg}^{-1} \mathrm{MPs}$ (Figure 1 \& Table 1). Exposure to MPs could impair the kidney and decrease its ability to secrete creatinine through reducing glomerular filtration. A study done by Hamed et al. (2019) showed that exposure of tilapia O. niloticus to MPs increased creatinine levels (Hamed, et al., 2019). No significant differences were found in the creatinine level in fish after being challenged with Y. ruckeri alone. However, creatinine concentration in fish co-exposed to both MPs and bacterial infections was significantly higher than the control group. This study showed that fish exposure to MPs challanged with $Y$. ruckeri could lead to a synergic effect on creatinine levels.

Results showed that bacterial infection of fish did not cause a significant change in triglyceride concentration. Fish exposure to MPs resulted in a meaningful increase in triglyceride concentration compared to the control group (Figure 1 \& Table 1). Simultaneous exposure of fish to MPs and challenge with Y. ruckeri significantly increased triglyceride concentrations. Bao et al. (2020) found that exposure of fish to xenobiotics could alter the expression of genes involved in lipid metabolism and adipogenesis (Bao, et al., 2020). Morover, increased metabolic expenditure after Y. ruckeri challenge and MPs exposure to maintain homeostasis and detoxification can lead to metabolite concentrations changes (Wang, et al., 2021). The glycerol in triglycerides can be converted to glucose (Wen, et al., 2021). Therefore, an increase in triglycerides may indirectly increase the blood glucose of fish exposed to MPs and $Y$. ruckeri. This study revealed that fish exposure to MPs combined with $Y$. ruckeri could lead to a synergic effect on the triglyceride levels. The triglyceride levels were elevated in the serum of common carp, C. carpio and freshwater pond turtles, E. orbicularis after treatment with MPs (Banaee, et al., 2019; Banaee, et al., 2020b).

There were no significant changes in the cholesterol levels in the blood of fish infected with $Y$. ruckeri. Treatment of fish with MPs alone and MPs combined with Y. ruckeri resulted in a significant reduction in cholesterol concentration. This study showed that fish co-exposure to MPs and $Y$. ruckeri could lead to a suppressive effect on the cholesterol levels (Figure 1 \& Table 1). Changes in the concentration of cholesterol in fish's blood showed an inverse trend of triglyceride concentration, which may be related to its different biological role. Cholesterol is not known as the primary energy source but is involved in the biosynthesis of biological membranes, steroid and corticosteroid hormones and bile acids (Wen, et al., 2021). Therefore, cholesterol depletion may be attributed to impaired cholesterol biosynthesis in the liver or its absorption in the intestine, increased biosynthesis rates of corticosteroid hormones, and bile acids. Porins and lipopolysaccharides play an essential role in increasing cytokinin biosynthesis in hepatocytes and macrophages (Portnyagina, et al., 2021). Hence, the liver tries to excrete cytokines by enhancing bile acids' biosynthesis to maintain biochemical homeostasis (Li, et al., 2006). A significant decrease in cholesterol levels was observed in the serum of African catfish, Clarias gariepinus exposed to MPs (Kim, et al., 2021).

High-density lipoprotein concentrations reduced significantly after fish exposure to Y. ruckeri and MPs alone and in combination. A significant decline was detected in low-density lipoprotein concentrations in the plasma of fish after coexposure to MPs and Y. ruckeri. Decreased LDL and HDL may be due to lower blood cholesterol levels (Figure 1 \& Table 1).

Total protein, globulins, and total immunoglobulins content in the plasma decreased significantly following fish exposure to $Y$. ruckeri and MPs alone and in combination. The globulin and total immunoglobulin levels in fish exposed to both MPs and bacteria were considerably lower than the other experimental groups. Co-exposure to MPs and bacteria resulted in a decrease in albumin in the plasma of fish (Figure $2 \&$ Table 1 ). 
Decreased total protein may be due to increased protein catabolic rate to counteract the toxicity of MPs and bacterial biotoxins. Morover, MPs may inhibit the absorption of essential amino acids and reduce food digestibility in the aquatic digestive system. Decreases in globulin, albumin, and immunoglobulin levels also reflect a decrease in total plasma protein. Damage to the intestinal epithelium of fish after challenge with $Y$. ruckeri may also prevent the absorption of essential amino acids. Furthermore, Fernandez et al. (2003) found that Yrp1 protease plays a critical role in the biodegradation of a wide variety of matrix and muscle proteins (Fernandez, et al., 2003). Therefore, the increased biodegradation rate of plasma proteins could decrease total proteins, albumin, and globulin. Total proteins, albumin, and globulin levels decreased in the serum of freshwater pond turtles, E. orbicularis exposed to MPs (Banaee, et al., 2020b).

Table 1: Evaluation of synergism of MPs and Y. ruckeri concerning the blood biochemical parameters 


\begin{tabular}{|c|c|c|c|c|c|c|c|c|c|c|c|}
\hline Parameters & Treatment & PE & $\mathrm{OE}$ & SR & CE & Parameters & Treatment & PE & OE & SR & CE \\
\hline \multirow[t]{4}{*}{ Glucose } & $\begin{array}{l}500 \\
\text { MPs\& 5\% } \\
\text { LD50 }\end{array}$ & 2.21 & 1.53 & 1.45 & $S$ & \multirow[t]{4}{*}{ LDL } & $\begin{array}{l}500 \\
\text { MPs\& 5\% } \\
\text { LD50 }\end{array}$ & 0.57 & 0.44 & 1.30 & $S$ \\
\hline & $\begin{array}{l}1000 \\
\text { MPs\& 5\% } \\
\text { LD50 }\end{array}$ & 2.16 & 1.97 & 1.10 & $S$ & & $\begin{array}{l}1000 \\
\text { MPs\& 5\% } \\
\text { LD50 }\end{array}$ & 0.34 & 0.77 & 0.44 & $A$ \\
\hline & $\begin{array}{l}500 \\
\text { MPs\& } \\
10 \% \text { LD50 }\end{array}$ & 2.53 & 1.85 & 1.37 & $S$ & & $\begin{array}{l}500 \\
\text { MPs\& } \\
10 \% \text { LD50 }\end{array}$ & 0.77 & 0.49 & 1.56 & $S$ \\
\hline & $\begin{array}{l}1000 \\
\text { MPs\& } \\
10 \% \text { LD50 }\end{array}$ & 2.48 & 1.80 & 1.38 & $S$ & & $\begin{array}{l}1000 \\
\text { MPs\& } \\
10 \% \text { LD50 }\end{array}$ & 0.46 & 0.72 & 0.64 & $A$ \\
\hline \multirow[t]{4}{*}{ Creatinine } & $\begin{array}{l}500 \\
\text { MPs\& 5\% } \\
\text { LD50 }\end{array}$ & 2.12 & 2.18 & 0.97 & $A$ & \multirow[t]{4}{*}{ Total protein } & $\begin{array}{l}500 \\
\text { MPs\& 5\% } \\
\text { LD50 }\end{array}$ & 0.64 & 0.66 & 0.97 & $A$ \\
\hline & $\begin{array}{l}1000 \\
\text { MPs\& 5\% } \\
\text { LD50 }\end{array}$ & 2.56 & 2.19 & 1.17 & $S$ & & $\begin{array}{l}1000 \\
\text { MPs\& 5\% } \\
\text { LD50 }\end{array}$ & 0.55 & 0.68 & 0.80 & $A$ \\
\hline & $\begin{array}{l}500 \\
\text { MPs\& } \\
10 \% \text { LD50 }\end{array}$ & 2.56 & 2.31 & 1.11 & $S$ & & $\begin{array}{l}500 \\
\text { MPs\& } \\
10 \% \text { LD50 }\end{array}$ & 0.61 & 0.66 & 0.92 & $A$ \\
\hline & $\begin{array}{l}1000 \\
\text { MPs\& } \\
10 \% \text { LD50 }\end{array}$ & 3.10 & 2.36 & 1.31 & $S$ & & $\begin{array}{l}1000 \\
\text { MPs\& } \\
10 \% \text { LD50 }\end{array}$ & 0.52 & 0.72 & 0.72 & $A$ \\
\hline \multirow[t]{4}{*}{ Triglyceride } & $\begin{array}{l}500 \\
\text { MPs\& 5\% } \\
\text { LD50 }\end{array}$ & 1.49 & 1.62 & 0.92 & $A$ & \multirow[t]{4}{*}{ Albumin } & $\begin{array}{l}500 \\
\text { MPs\& 5\% } \\
\text { LD50 }\end{array}$ & 0.89 & 0.78 & 1.14 & $S$ \\
\hline & $\begin{array}{l}1000 \\
\text { MPs\& 5\% } \\
\text { LD50 }\end{array}$ & 1.73 & 1.68 & 1.03 & $S$ & & $\begin{array}{l}1000 \\
\text { MPs\& 5\% } \\
\text { LD50 }\end{array}$ & 0.79 & 0.85 & 0.93 & $A$ \\
\hline & $\begin{array}{l}500 \\
\text { MPs\& } \\
10 \% \text { LD50 }\end{array}$ & 1.59 & 1.52 & 1.05 & $S$ & & $\begin{array}{l}500 \\
\text { MPs\& } \\
10 \% \text { LD50 }\end{array}$ & 0.96 & 0.81 & 1.19 & $S$ \\
\hline & $\begin{array}{l}1000 \\
\text { MPs\& } \\
10 \% \text { LD50 }\end{array}$ & 1.85 & 1.76 & 1.05 & $S$ & & $\begin{array}{l}1000 \\
\text { MPs\& } \\
10 \% \text { LD50 }\end{array}$ & 0.85 & 0.93 & 0.92 & $A$ \\
\hline \multirow[t]{4}{*}{ Cholesterol } & $\begin{array}{l}500 \\
\text { MPs\& 5\% } \\
\text { LD50 }\end{array}$ & 0.61 & 0.45 & 1.34 & $S$ & \multirow[t]{4}{*}{ Globulins } & $\begin{array}{l}500 \\
\text { MPs\& 5\% } \\
\text { LD50 }\end{array}$ & 0.49 & 0.57 & 0.86 & A \\
\hline & $\begin{array}{l}1000 \\
\text { MPs\& 5\% } \\
\text { LD50 }\end{array}$ & 0.35 & 0.59 & 0.58 & $A$ & & $\begin{array}{l}1000 \\
\text { MPs\& 5\% } \\
\text { LD50 }\end{array}$ & 0.40 & 0.57 & 0.70 & A \\
\hline & $\begin{array}{l}500 \\
\text { MPs\& } \\
10 \% \text { LD50 }\end{array}$ & 0.61 & 0.38 & 1.60 & $S$ & & $\begin{array}{l}500 \\
\text { MPs\& } \\
10 \% \text { LD50 }\end{array}$ & 0.41 & 0.56 & 0.74 & A \\
\hline & $\begin{array}{l}1000 \\
\text { MPs\& } \\
10 \% \text { LD50 }\end{array}$ & 0.35 & 0.43 & 0.81 & $A$ & & $\begin{array}{l}1000 \\
\text { MPs\& } \\
10 \% \text { LD50 }\end{array}$ & 0.34 & 0.57 & 0.59 & A \\
\hline HDL & $\begin{array}{l}500 \\
\text { MPs\& 5\% }\end{array}$ & 0.61 & 0.55 & 1.10 & $S$ & $\begin{array}{l}\text { Total } \\
\text { immunoglobulins }\end{array}$ & $\begin{array}{l}500 \\
\text { MPs\& 5\% }\end{array}$ & 0.56 & 0.38 & 1.46 & $S$ \\
\hline
\end{tabular}




\begin{tabular}{|c|c|c|c|c|c|c|c|c|c|c|}
\hline & \multicolumn{5}{|l|}{ LD50 } & \multicolumn{5}{|l|}{ LD50 } \\
\hline & $\begin{array}{l}1000 \\
\text { MPs\& 5\% } \\
\text { LD50 }\end{array}$ & 0.51 & 0.80 & 0.63 & $A$ & $\begin{array}{l}1000 \\
\text { MPs\& 5\% } \\
\text { LD50 }\end{array}$ & 0.45 & 0.41 & 1.09 & $S$ \\
\hline & $\begin{array}{l}500 \\
\text { MPs\& } \\
10 \% \text { LD50 }\end{array}$ & 0.65 & 0.60 & 1.08 & $S$ & $\begin{array}{l}500 \\
\text { MPs\& } \\
10 \% \text { LD50 }\end{array}$ & 0.56 & 0.32 & 1.73 & $S$ \\
\hline & $\begin{array}{l}1000 \\
\text { MPs\& } \\
10 \% \text { LD50 }\end{array}$ & 0.54 & 0.77 & 0.70 & $A$ & $\begin{array}{l}1000 \\
\text { MPs\& } \\
10 \% \text { LD50 }\end{array}$ & 0.45 & 0.36 & 1.23 & $S$ \\
\hline \multirow[t]{4}{*}{ LDL } & $\begin{array}{l}500 \\
\text { MPs\& 5\% } \\
\text { LD50 }\end{array}$ & 0.57 & 0.44 & 1.30 & $S$ & & & & & \\
\hline & $\begin{array}{l}1000 \\
\text { MPs\& 5\% } \\
\text { LD50 }\end{array}$ & 0.34 & 0.77 & 0.44 & A & & & & & \\
\hline & $\begin{array}{l}500 \\
\text { MPs\& } \\
10 \% \text { LD50 }\end{array}$ & 0.77 & 0.49 & 1.56 & $S$ & & & & & \\
\hline & $\begin{array}{l}1000 \\
\text { MPs\& } \\
10 \% \text { LD50 }\end{array}$ & 0.46 & 0.72 & 0.64 & $A$ & & & & & \\
\hline
\end{tabular}

- Predicated effect: PE, Observed effect: OE, Synergy ratio: SR, Combined effect: CE, Synergistic effect: S, Suppressive effect:

AST (SGOT) and ALT (SGPT) are non-specific enzymes found in two different cytoplasmic and mitochondrial isoforms in all tissues (McGill, 2016; Wang \& Chen, 2018). SGOT and SGPT play an essential role in glutathione biosynthesis and glycogen renewal in liver cells (Ellinger, et al., 2011). Furthermore, aminotransferases maintain a balance between NAD ${ }^{+} /$ NADH in cells (McGill, 2016). The role of aminotransferases in glycerol regeneration in adipose tissues and neurotransmitter biosynthesis in the neuroglia is considerable (Wang \& Chen, 2018). Exposure of fish to MPs and/or $Y$. ruckeri resulted in a significant increase in SGOT, ALP, and LDH activities. Challenge of fish with Y. ruckeri had no significant effect on SGPT activity (Figure 3 \& Table 2). Damage to hepatocytes may lead to increased SGOT, SGPT, ALP and LDH activities. The results showed that SGPT activity significantly increased in fish exposed to $1000 \mathrm{mg} \mathrm{Kg}^{-1} \mathrm{MPs}$ (Figure 3 \& Table 2). Furthermore, combined exposure to MPs and bacteria increased SGPT activity in fish plasma. The change in SGOT, SGPT, LDH, and ALP activities can be attributed to the hepatotoxicity effect of bacterial lipopolysaccharide (Beheshti, et al., 2021). Also, porins can significantly affect cellular biochemical homeostasis by disrupting the selective permeability of cell membranes (Portnyagina, et al., 2021). ALP is a transmembrane metalloenzyme involved in protein phosphorylation, cell growth, apoptosis, and cell migration (Derikvandy, et al., 2020). Therefore, any damage to the cell membrane can lead to a change in ALP activity in the blood (Banaee, et al., 2019). ALP activity significantly increased in the serum of Symphysodon aequifasciatus and O. niloticus after exposure to MPs (Wen, et al., 2018; Hamed, et al., 2019). In serum of turtle (Emys orbicularis), Banaee et al. (2021) also found that SGOT, SGPT, and ALP activity increased after MPs' exposure.

LDH plays a vital role in converting lactate to pyruvate, NAD to NADH and vice versa (Soleimany, et al., 2016). LDH is an indicator of hypoxia and mitochondrial oxidation function. Also, an increase in extracellular LDH can indicate cell death or necrosis (Maes, et al., 2015). Increased LDH activity was detected in the $C$. carpio and S. aequifasciatus exposed to MPs combined with Cd (Wen, et al., 2018; Banaee, et al., 2019). GGT is an anchorage enzyme in the cell membrane that plays a unique role in the gamma-glutamyl cycle in the biosynthesis and biodegradation of glutathione and detoxification from 
xenobiotics (Hatami, et al., 2019). Compared with the reference group, GGT activity decreased in the plasma of fish exposed to MPs and Y. ruckeri individually and concurrently (Figure 3 \& Table 2). Changes in the catalytic domain of the GGT can lead to its inactivation. GGT is often degraded after inactivation, and its metabolites are excreted in the bile (Fornaciari, et al., 2014). The relationship between decreased GGT activity in the blood and increased biliary excretion of its metabolites has also been demonstrated (Li \& Chiang, 2014). Decreased GGT activity in serum of freshwater pond turtles (E. orbicularis) exposed to MPs may indicate a reduction in detoxification capacity in hepatocytes (Banaee, et al., 2020b). Damage to the intestinal epithelium after bacterial challenge and exposure to MPs may lead to gastrointestinal disorders. Therefore, a reduction in GGT activity can be attributed to the disturbance in the absorption of minerals and vitamins.

A significant decrease was observed in CAT activity in the hepatocyte of fish after co-exposure to MPs and Y. ruckeri. The result shows that MPs combined with Y. ruckeri inhibited CAT (Figure 4 \& Table 2). CAT plays a vital role in the breakdown of hydrogen peroxide (Banaee, et al., 2013). Therefore, inhibition of CAT activity may lead to an increase in $\mathrm{H}_{2} \mathrm{O}_{2}$ at the cellular level. However, there was no significant difference in CAT activity between the MPs, bacterial groups alone and the control group. A decrease in the CAT activity was reported in the Oryzias melastigma and Danio rerio following exposure to the MPs (Wang, et al., 2019; Wan, et al., 2019). GPx activity in hepatocytes of fish challenged with $10 \%$ LD $_{50}$ Y. ruckeri was significantly lower than the control group. Exposure of fish to MPs alone and MPs combined with Y. ruckeri reduced GPX activity in hepatocytes (Figure 4 \& Table 2). GPx is an enzyme involved in GSH-related antioxidant defense mechanisms that can neutralize organic peroxides (ROOH) and hydroperoxides (Banaee, et al., 2013). Therefore, decreased GPx activity can lead to oxidative stress in fish exposed to MPs and Y. ruckeri. The GPx activity significantly decreased in D. rerio after exposure to MPs (Umamaheswari, et al., 2020). Significant activation of SOD occurred after fish exposure to MPs and/or Y. ruckeri (Figure $4 \&$ Table 2). SOD is the only antioxidant enzyme that neutralizes the superoxide anion by transforming this ROS to oxygen and hydrogen peroxide (Banaee, et al., 2013). Increased SOD activity may be a physiological response to enhanced superoxide anions in cells. SOD activity significantly increased in the liver of goldfish, Carassius auratus, and common carp, C. carpio after exposure to MPs (Xia, et al., 2020; Yang, et al., 2020).

Exposure to MPs and/or Y. ruckeri resulted in a significant decrease in total antioxidant levels in fish's hepatocyte. MDA content in the hepatocytes of fish exposed to $500 \mathrm{mg} \mathrm{Kg}^{-1} \mathrm{MPs}$ and $5 \% \mathrm{LD}_{50}$ Y. ruckeri alone did not show any significant changes to the control group. However, MDA content was increased considerably in the hepatocytes of fish exposed to $1000 \mathrm{mg} \mathrm{Kg}^{-1} \mathrm{MPs}$ and $10 \% \mathrm{LD}_{50}$ Y. ruckeri alone. Co-exposure of fish to MPs and Y. ruckeri increased MDA levels. Raised levels of lipid peroxidation indicate an increase in the rate of reactive oxygen species production (Figure 4 \& Table 2). A significant increase in MDA was observed in the O. niloticus (Hamed, et al., 2019), (Ding, et al., 2018), S. aequifasciatus (Wen, et al., 2018), C. auratus (Xia, et al., 2020), C. carpio (Yang, et al., 2020), D. rerio (Umamaheswari, et al., 2020), and Dicentrarchus labrax (Barboza \& Guilhermino, 2018).

Changes in oxidative stress biomarkers indicated oxidative stress in fish hepatocytes in the challenge with $Y$. ruckeri and MPs. Exposure of fish to MPs can disrupt the balance between reactive oxygen species' production rate and the antioxidant defense capacity of cells. Hence, when the antioxidant defense capacity is insufficient to quench the ROS produced, it will lead to oxidative damage (Figure $4 \&$ Table 2)

Table 2: Evaluation of synergism of MPs and Y. ruckeri concerning the plasma enzyme activities and oxidative biomarkers 


\begin{tabular}{|c|c|c|c|c|c|c|c|c|c|c|c|}
\hline Parameters & Treatment & $\mathrm{PE}$ & $\mathrm{OE}$ & SR & CE & Parameters & Treatment & PE & $\mathrm{OE}$ & SR & CE \\
\hline \multirow[t]{4}{*}{ SGOT } & $\begin{array}{l}500 \text { MPs\& } \\
5 \% \text { LD50 }\end{array}$ & 3.49 & 3.01 & 1.16 & S & \multirow[t]{4}{*}{ CAT } & $\begin{array}{l}500 \text { MPs\& } \\
5 \% \text { LD50 }\end{array}$ & 0.89 & 0.64 & 1.40 & $S$ \\
\hline & $\begin{array}{l}1000 \text { MPs } \& \\
5 \% \text { LD } 50\end{array}$ & 3.91 & 2.78 & 1.41 & $S$ & & $\begin{array}{l}1000 \text { MPs\& } \\
5 \% \text { LD50 }\end{array}$ & 1.09 & 0.60 & 1.82 & $S$ \\
\hline & $\begin{array}{l}500 \text { MPs\& } \\
10 \% \text { LD50 }\end{array}$ & 3.61 & 2.35 & 1.54 & S & & $\begin{array}{l}500 \text { MPs\& } \\
10 \% \text { LD50 }\end{array}$ & 0.93 & 0.44 & 2.13 & $S$ \\
\hline & $\begin{array}{l}1000 \text { MPs\& } \\
10 \% \text { LD50 }\end{array}$ & 4.04 & 2.97 & 1.36 & S & & $\begin{array}{l}1000 \text { MPs\& } \\
10 \% \text { LD50 }\end{array}$ & 0.70 & 0.78 & 0.90 & $A$ \\
\hline \multirow[t]{4}{*}{ SGPT } & $\begin{array}{l}500 \text { MPs\& } \\
5 \% \text { LD50 }\end{array}$ & 3.75 & 2.38 & 1.57 & $S$ & \multirow[t]{4}{*}{ GPx } & $\begin{array}{l}500 \text { MPs\& } \\
5 \% \text { LD50 }\end{array}$ & 0.68 & 0.66 & 1.04 & $S$ \\
\hline & $\begin{array}{l}1000 \text { MPs } \& \\
5 \% \text { LD50 }\end{array}$ & 6.11 & 2.71 & 2.25 & $S$ & & $\begin{array}{l}1000 \text { MPs } \& \\
5 \% \text { LD50 }\end{array}$ & 0.65 & 0.60 & 1.09 & $S$ \\
\hline & $\begin{array}{l}500 \text { MPs\& } \\
10 \% \text { LD50 }\end{array}$ & 2.97 & 2.60 & 1.15 & $S$ & & $\begin{array}{l}500 \text { MPs\& } \\
10 \% \text { LD50 }\end{array}$ & 0.63 & 0.59 & 1.08 & $S$ \\
\hline & $\begin{array}{l}1000 \text { MPs\& } \\
10 \% \text { LD50 }\end{array}$ & 4.85 & 2.48 & 1.96 & S & & $\begin{array}{l}1000 \text { MPs\& } \\
10 \% \text { LD50 }\end{array}$ & 3.08 & 2.68 & 1.15 & $S$ \\
\hline \multirow[t]{4}{*}{ ALP } & $\begin{array}{l}500 \text { MPs\& } \\
5 \% \text { LD50 }\end{array}$ & 4.78 & 2.59 & 1.84 & S & \multirow[t]{4}{*}{ SOD } & $\begin{array}{l}500 \text { MPs\& } \\
5 \% \text { LD50 }\end{array}$ & 4.03 & 2.98 & 1.35 & $\mathrm{~S}$ \\
\hline & $\begin{array}{l}1000 \text { MPs } \& \\
5 \% \text { LD } 50\end{array}$ & 4.42 & 2.47 & 1.79 & $S$ & & $\begin{array}{l}1000 \text { MPs } \& \\
5 \% \text { LD50 }\end{array}$ & 3.99 & 3.05 & 1.31 & $S$ \\
\hline & $\begin{array}{l}500 \text { MPs\& } \\
10 \% \text { LD50 }\end{array}$ & 5.84 & 2.13 & 2.75 & $S$ & & $\begin{array}{l}500 \text { MPs\& } \\
10 \% \text { LD50 }\end{array}$ & 5.22 & 3.28 & 1.59 & $S$ \\
\hline & $\begin{array}{l}1000 \text { MPs\& } \\
10 \% \text { LD50 }\end{array}$ & 5.40 & 3.53 & 1.53 & S & & $\begin{array}{l}1000 \text { MPs\& } \\
10 \% \text { LD50 }\end{array}$ & 0.59 & 0.86 & 0.69 & $A$ \\
\hline \multirow[t]{4}{*}{ LDH } & $\begin{array}{l}500 \text { MPs\& } \\
5 \% \text { LD50 }\end{array}$ & 2.87 & 1.75 & 1.64 & $S$ & \multirow[t]{4}{*}{ MDA } & $\begin{array}{l}500 \text { MPs\& } \\
5 \% \text { LD50 }\end{array}$ & 0.60 & 0.73 & 0.82 & $A$ \\
\hline & $\begin{array}{l}1000 \text { MPs } \& \\
5 \% \text { LD50 }\end{array}$ & 2.63 & 1.83 & 1.44 & $S$ & & $\begin{array}{l}1000 \text { MPs } \& \\
5 \% \text { LD50 }\end{array}$ & 0.53 & 0.69 & 0.76 & $A$ \\
\hline & $\begin{array}{l}500 \text { MPs\& } \\
10 \% \text { LD50 }\end{array}$ & 2.58 & 1.84 & 1.40 & $S$ & & $\begin{array}{l}500 \text { MPs\& } \\
10 \% \text { LD50 }\end{array}$ & 0.53 & 0.56 & 0.95 & $A$ \\
\hline & $\begin{array}{l}1000 \text { MPs\& } \\
10 \% \text { LD50 }\end{array}$ & 2.36 & 1.78 & 1.33 & $S$ & & $\begin{array}{l}1000 \text { MPs } \& \\
10 \% \text { LD50 }\end{array}$ & 170 & 35.00 & 4.88 & $A$ \\
\hline \multirow[t]{4}{*}{ GGT } & $\begin{array}{l}500 \text { MPs\& } \\
5 \% \text { LD50 }\end{array}$ & 0.49 & 0.45 & 1.09 & $S$ & \multirow[t]{4}{*}{$\begin{array}{l}\text { Total } \\
\text { antioxidant }\end{array}$} & $\begin{array}{l}500 \text { MPs\& } \\
5 \% \text { LD50 }\end{array}$ & 212 & 36.52 & 5.82 & $S$ \\
\hline & $\begin{array}{l}1000 \text { MPs } \& \\
5 \% \text { LD } 50\end{array}$ & 0.36 & 0.46 & 0.78 & $A$ & & $\begin{array}{l}1000 \text { MPs\& } \\
5 \% \text { LD50 }\end{array}$ & 197 & 42.67 & 4.62 & $S$ \\
\hline & $\begin{array}{l}500 \text { MPs\& } \\
10 \% \text { LD50 }\end{array}$ & 0.38 & 0.41 & 0.93 & $A$ & & $\begin{array}{l}500 \text { MPs\& } \\
10 \% \text { LD50 }\end{array}$ & 245 & 47.24 & 5.19 & $S$ \\
\hline & $\begin{array}{l}1000 \text { MPs\& } \\
10 \% \text { LD50 }\end{array}$ & 0.28 & 0.43 & 0.66 & $A$ & & $\begin{array}{l}1000 \text { MPs\& } \\
10 \% \text { LD50 }\end{array}$ & 0.89 & 0.64 & 1.40 & $S$ \\
\hline
\end{tabular}

- Predicated effect: PE, Observed effect: OE, Synergy ratio: SR, Combined effect: CE, Synergistic effect: S, Suppressive effect 
(Ryckaert, et al., 2010) and (Guijarro, et al., 2018) found that inoculation of trout renal macrophages with $Y$. ruckeri in the in vitro condition can induce reactive oxygen species production. Thus, changes in antioxidant enzyme activities and cellular antioxidant capacity may have been due to ROS increase by macrophages of fish after challenging with $Y$. ruckeri.

Morover, bacterial metalloproteinases may activate mechanisms involved in producing reactive oxygen species that could lead to oxidative stress (Dasgupta, et al., 2010).

\section{Conclusion}

This study showed that fish exposure to doses of 5 and $10 \% L_{50}$ of $Y$. ruckeri did not significantly change some clinical parameters. However, simultaneous exposure to MPs and $Y$. ruckeri resulted in changes in all clinical parameters. These results indicated that MPs have been able to have a synergistic effect on Y. ruckeri pathogenesis.

\section{Declarations}

\section{Acknowledgement}

This study was supported by a grant from Shiraz University. Also, the authors appreciate Maryam Banaie's assistance for proofreading the manuscript.

\section{Conflict of interest}

The authors declare that they have no conflict of interest.

\section{Ethics approval and consent to participate}

In this study, none of the authors used human beings as research subjects. International, national and institutional guidelines for the care and use of animals were followed. Experimental protocols were done following the Iranian animal ethics framework under the supervision of the Iranian Society for the Prevention of Cruelty to Animals and Shiraz University Research Council (SURC973/46-2679-2).

\section{Consent to Publish}

In the present study, there was no individual person's data in any form (including any individual details, images or videos).

Funding: This study is a product of PhD thesis No. 9531721, financially supported by a research grant from Shiraz University. The financial support of Shiraz University in performing this research is gratefully acknowledged.

\section{Authors Contributions}

Banihashemi: PhD. Student, Contribution: Investigation, Project administration

Siyavash Soltanian: Associate Professor (Veterinary), Contribution : Super-advaiser

Amin Gholamhosseini, Assistance Professor (Veterinary), Contribution: Super-advaiser , Cooperation in project implementation, Writing - Original Draft

Mahdi Banaee, Assistance Professor (Aquaculture and Ecotoxicology), Contribution: Advaiser, Validation, Formal analysis, Writing - Original Draft

\section{Availability of data and materials}


The data that support the findings of this study are available from Shiraz University but restrictions apply to the availability of these data, which were used under license for the current study, and so are not publicly available. Data are however available from the authors upon reasonable request and with permission of Shiraz University.

\section{References}

1. Banaee, M., \& Shakeri, R. (2021). The effect of microplastics on hematological and biochemical parameters in aquatic animals. Journal of Aquaculture Sciences, 8(15): 141-160.

2. Banaee, M., Gholamhosseini, A., Sureda, A., Soltanian, S., Fereidouni, M. S., \& Ibrahim, A. T. (2020b). Effects of microplastic exposure on the blood biochemical parameters in the pond turtle (emys orbicularis). Environmental Science and Pollution Research, doi:10.1007/s11356-020-11419-2.

3. Banaee, M., Soltanian, S., Sureda, A., Gholamhosseini, A., B, N. H., Akhlaghi, M., \& Derikvandy, A. (2019). Evaluation of single and combined effects of cadmium and micro-plastic particles on biochemical and immunological parameters of common carp (Cyprinus carpio). Chemosphere, 236, 124335. doi: 10.1016/j.chemosphere.2019.07.066.

4. Banaee, M., Sureda, A., Mirvaghefi, A. R., \& Ahmadi, K. (2013). Biochemical and histological changes in the liver tissue of rainbow trout (Oncorhynchus mykiss) exposed to sub-lethal concentrations of diazinon. Fish Physiology and Biochemistry, 39(3): 489-501. doi: 10.1007/s10695-012-9714-1.

5. Banaee, M., Tahery, S., Nematdoost Haghi, B., Shahafve, S., \& Vaziriyan, M. (2019). Blood biochemical changes in common carp (Cyprinus carpio) upon co-exposure to titanium dioxide nanoparticles and paraquat. Iranian Journal of Fisheries Sciences, 18(2), 242-255. doi:10.22092/ijfs.2019.118174.

6. Bao, Z., Zhao, Y., Wu, A., Lou, Z., Lu, H., Yu, Q., . . Jin, Y. (2020). Sub-chronic carbendazim exposure induces hepatic glycolipid metabolism disorder accompanied by gut microbiota dysbiosis in adult zebrafish (Daino rerio). Science of The Total Environment, 739. 140081. doi: 10.1016/j.scitotenv.2020.140081.

7. Beheshti, F., Hosseini, M., Taheri Sarvtin, M., Kamali, A., \& Anaeigoudari, A. (2021). Protective effect of aminoguanidine against lipopolysaccharide-induced hepatotoxicity and liver dysfunction in rat. Drug and Chemical Toxicology, 44(2): 215-221. doi: 10.1080/01480545.2018.1561712.

8. Bhagat, J., Zang, L., Nishimura, N., \& Shimada, Y. (2020). Zebrafish: An emerging model to study microplastic and nanoplastic toxicity. Science of The Total Environment, 728, 138707. doi: 10.1016/j.scitotenv.2020.138707.

9. Brandts, I., Teles, M., Tvarijonaviciute, A., Pereira, M. L., Martins, M. A., Tort, L., \& Oliveira, M. (2018). Effects of polymethylmethacrylate nanoplastics on Dicentrarchus labrax. Genomics, 110(6), 435-441. doi: 10.1016/j.ygeno.2018.10.006.

10. Chen, Q., Lv, W., Jiao, Y., Liu, Z., Li, Y., Cai, M., . . Zhou, W. Z. (2020). Effects of exposure to waterborne polystyrene microspheres on lipid metabolism in the hepatopancreas of juvenile redclaw crayfish, Cherax quadricarinatus. Aquat Toxicol, 224, 105497. doi: 10.1016/j.aquatox.2020.105497.

11. Dasgupta, J., Kar, S., Liu, R., Joseph, J., Kalayanaram, B., Remington, S. J., . . Melendez, J. A. (2010). Reactive Oxygen Species Control Senescence-Associated Matrix Metalloproteinase-1 through c-Jun-N-Terminal Kinase. Journal of Cell Physiology, 225(1): 52-62. doi: doi: 10.1002/jcp.22193.

12. Derikvandy, A., Pourkhabbaz, H. R., Banaee, M., Sureda, A., Haghi, N., \& Pourkhabbaz, A. R. (2020). Genotoxicity and oxidative damage in zebrafish (danio rerio) after exposure to effluent from ethyl alcohol industry. Chemosphere, 251: 126609. doi:10.1016/j.chemosphere.2020.126609.

13. Ding, J, Zhang, S, M, R., Zou, ... Zhu, W. (2018). Accumulation, tissue distribution, and biochemical effects of polystyrene microplastics in the freshwater fish red tilapia (Oreochromis niloticus). Environmental Pollution, $238,1-9$. doi: 10.1016/j.envpol.2018.03.001.

14. Ding, J., Huang, Y., Liu, S., Zhang, S., Zou, H., Wang, Z., . . Geng, J. (2020). Toxicological effects of nano- and micropolystyrene plastics on red tilapia: Are larger plastic particles more harmless? Journal of Hazardous Materials, 396,

Page $13 / 19$ 
122693. doi: 10.1016/j.jhazmat.2020.122693.

15. Ellinger, J. J., Lewis, I. A., \& Markley, J. L. (2011). Role of aminotransferases in glutamate metabolism of human erythrocytes. Journal of Biomolecular NMR, 49(3), 221-229. doi: 10.1007/s10858-011-9481-9.

16. Fernandez, L., Lopez, J. R., Secades, P., Menendez, A., Marquez, I., \& Guijarro, J. A. (2003). In Vitro and In Vivo Studies of the Yrp1 Protease from Yersinia ruckeri and Its Role in Protective Immunity against Enteric Red Mouth Disease of Salmonids. Applied and Environmental Microbiology, 69(12): 7328-7335. doi: 10.1128/AEM.69.12.7328-7335.2003.

17. Fornaciari, I., Fierabracci, V., Corti, A., Elawadi, H. A., Lorenzini, E., Emdin, M., . . Franzini, M. (2014). Gammaglutamyltransferase fractions in human plasma and bile: Characteristic and biogenesis. PLoS One, 9(2), e88532.

18. Frias, J. P., \& Roisin Nash, R. (2019). Microplastics: Finding a consensus on the definition. Marine Pollution Bulletin, 138, 145-147. doi: 10.1016/j.marpolbul.2018.11.022.

19. Hamed, M., Soliman, H. A., Osman, A. G., \& Sayed, A. E. (2019). Assessment the effect of exposure to microplastics in Nile Tilapia (Oreochromis niloticus) early juvenile: I. blood biomarkers. Chemosphere, 228, 345-350. doi: 10.1016/j.chemosphere.2019.04.153.

20. Hatami, M., Banaee, M., \& Nematdoost Haghi, B. (2019). Sub-lethal toxicity of chlorpyrifos alone and in combination with polyethylene glycol to common carp (Cyprinus carpio). Chemosphere, 219: 981-988. doi: 10.1016/j.chemosphere.2018.12.077.

21. Iheanacho, S. C., Igberi, C., Amadi-Eke, A., Chinonyerem, D., Iheanacho, A., \& Avwemoya, F. (2020). Biomarkers of neurotoxicity, oxidative stress, hepatotoxicity and lipid peroxidation in clarias gariepinus exposed to melamine and polyvinyl chloride. Biomarkers, 25(7), 603-610. doi:10.1080/1354750X.2020.1821777.

22. Jovanović, B. (2017). Ingestion of microplastics by fish and its potential consequences from a physical perspective. Integrated Environmental Assessment and Management, 13(3), 510-515. doi:10.1002/ieam.1913.

23. Kang, H. M., Byeon, E., Jeong, H., Kim, M. S., Chen, Q., \& Lee, J. S. (2021). Different effects of nano- and microplastics on oxidative status and gut microbiota in the marine medaka Oryzias melastigma. Journal of Hazardous Materials, 405, 124207. doi: 10.1016/j.jhazmat.2020.124207.

24. Kim, J. H., Yu, Y. B., \& Choi, J. H. (2021). Toxic effects on bioaccumulation, hematological parameters, oxidative stress, immune responses and neurotoxicity in fish exposed to microplastics: A review. Journal of Hazardous Materials, 413, 125423. doi: 10.1016/j.jhazmat.2021.125423.

25. Kumar, G., Menanteau-Ledouble, S., Saleh, M., \& El-Matbouli, M. (2015). Yersinia ruckeri, the causative agent of enteric redmouth disease in fish. Veterinary Research, 46: 103. doi: 10.1186/s13567-015-0238-4.

26. Li, T., \& Chiang, J. Y. (2014). Bile acid signaling in metabolic disease and drug therapy. Pharmacological Reviews, 66(4), 943-983. doi: 10.1124/pr.113.008201.

27. Li, T., Jahan, A., \& Chiang, J. Y. (2006). Bile acids and cytokines inhibit the human cholesterol 7a-hydroxylase gene via the JNK/c-jun pathway in human liver cells. Hepatology, 43(6): 1202-1210. doi: 10.1002/hep.21183.

28. Maes, M., Vanhaecke, T., Cogliati, B., Yanguas, S. C., Willebrords, J., Rogiers, V., \& Vinken, M. (2015). Measurement of apoptotic and necrotic cell death in primary hepatocyte cultures. Methods in Molecular Biology, 1250, 349-361. doi: 10.1007/978-1-4939-2074-7_27.

29. McGill, M. R. (2016). The past and present of serum aminotransferases and the future of liver injury biomarkers. Experimental and Clinical Science Journal, 15, 817-828. doi: 10.17179/excli2016-800.

30. Nematdoost Haghi, B., \& Banaee, M. (2017). Effects of micro-plastic particles on paraquat toxicity to common carp (cyprinus carpio): Biochemical changes. International Journal of Environmental Science and Technology, 14(3), 521530. doi:10.1007/s13762-016.

31. Pannetier, P., Morin, B., Bihanic, F. L., Dubreil, L., Clérandeau, C., Chouvellon, F., . . Cachot, J. (2020). Environmental samples of microplastics induce significant toxic effects in fish larvae. Environment International, 134, 105047. doi: 10.1016/j.envint.2019.105047.

Page 14/19 
32. Portnyagina, O., Chistyulin, D., Dyshlovoy, S., Davidova, V., Khomenko, V., Shevchenko, L., \& Novikova, O. (2021). OmpF porin from Yersinia ruckeri as pathogenic factor: Surface antigenic sites and biological properties. Microbial Pathogenesis, 150: 104694. doi: 10.1016/j.micpath.2020.104694.

33. Qiao, R., Deng, Y., Zhang, S., Wolosker, M. B., Zhu, Q., Ren, H., \& Zhang, Y. (2019a). Accumulation of different shapes of microplastics initiates intestinal injury and gut microbiota dysbiosis in the gut of zebrafish. Chemosphere, 236, 124334. doi: 10.1016/j.chemosphere.2019.07.065.

34. Qiao, R., Lu, K., Deng, Y., Ren, H., \& Zhang, Y. (2019b). Combined effects of polystyrene microplastics and natural organic matter on the accumulation and toxicity of copper in zebrafish. Science of The Total Environment, 682, 128137. doi: 10.1016/j.scitotenv.2019.05.163.

35. Soleimany, V., Banaee, M., Mohiseni, M., Nematdoost Hagi, B., \& Mousavi Dehmourdi, L. (2016). Evaluation of preclinical safety and toxicology of althaea officinalis extracts as naturopathic medicine for common carp (cyprinus carpio). Iranian Journal of Fisheries Sciences, 15(2): 613-629.

36. Wang, C., \& Chen, H. Y. (2018). Cytosolic aspartate aminotransferase mediates the mitochondrial membrane potential and cell survival by maintaining the calcium homeostasis of BV2 microglia. NeuroReport, 29(2), 99-105. doi: 10.1097/WNR.0000000000000914.

37. Wang, W., Ge, J., \& Yu, X. (2020). Bioavailability and toxicity of microplastics to fish species: A review. Ecotoxicology and Environmental Safety, 189, 109913. doi: 10.1016/j.ecoenv.2019.109913.

38. Wang, Y., Zhao, H., Guo, M., Mu, M., Zong, H., \& Xing, M. (2021). Co-administration of zinc for treating and preventing arsenism in common carp Cyprinus carpio: An alternative to avoid physiological and cellular damages. Aquaculture, 531: 735965. doi: 10.1016/j.aquaculture.2020.735965.

39. Wen, B., Jin, S. R., Chen, Z. Z., Gao, J. Z., Liu, Y. N., Liu, J. H., \& Feng, X. S. (2018). Single and combined effects of microplastics and cadmium on the cadmium accumulation, antioxidant defence and innate immunity of the discus fish (Symphysodon aequifasciatus). Environmental Pollution, 243, 462-471. doi: 10.1016/j.envpol.2018.09.029.

40. Wen, X., Chu, P., Xu, J., Wei, X., Fu, D., Wang, T., \& Yin, S. (2021). Combined effects of low temperature and salinity on the immune response, antioxidant capacity and lipid metabolism in the pufferfish (Takifugu fasciatus). Aquaculture, 531: 735668. doi: 10.1016/j.aquaculture.2020.735866.

41. Zhang, C., Wang, J., Zhou, A., Ye, Q., Feng, Y., Wang, Z., . . Zou, J. (2021). Species-specific effect of microplastics on fish embryos and observation of toxicity kinetics in larvae. Journal of Hazardous Materials, 403, 123948. doi: 10.1016/j.jhazmat.2020.123948.

\section{Figures}



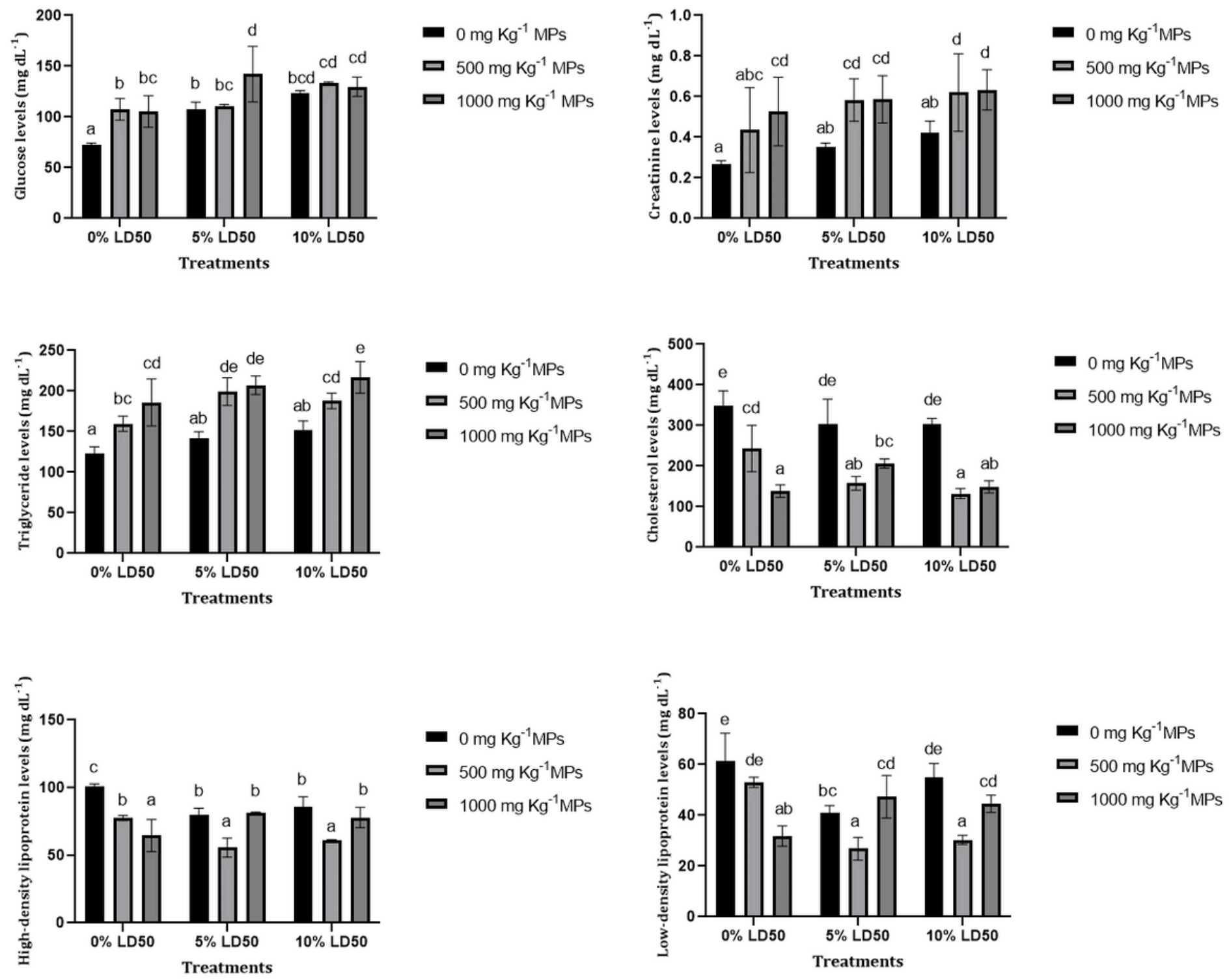

Figure 1

Changes of glucose, creatinine, cholesterol, triglyceride, high-density lipoprotein, and low-density lipoprotein levels in the blood of rainbow trout after exposure to MPs and Y. ruckeri. Results are illustrated as mean \pm SD. Significant differences between groups were identified by alphabetical characters $(P<0.05)$. 

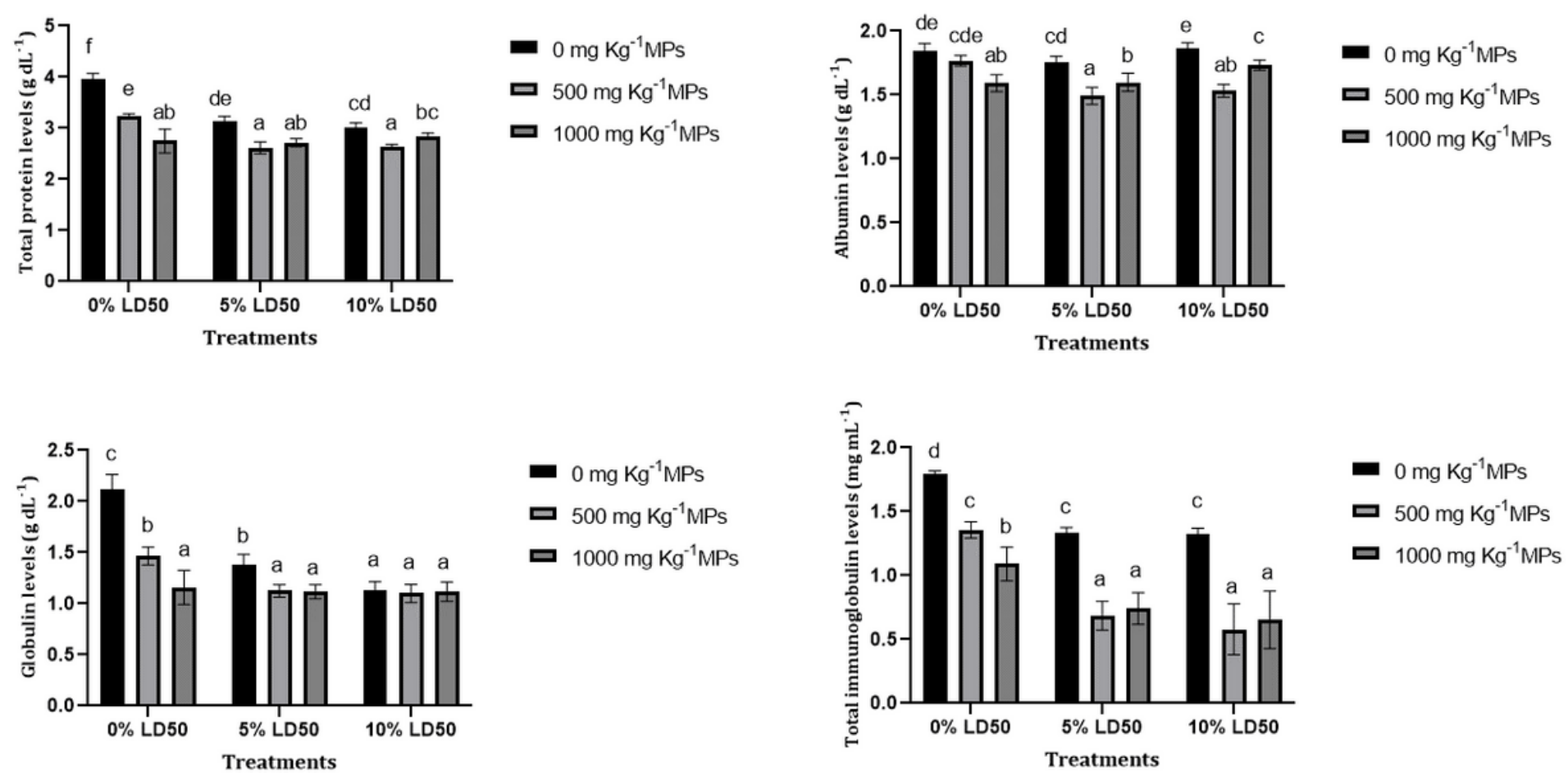

Figure 2

Changes of total protein, albumin, glubolin, and total immunoglubolins levels in the blood of rainbow trout after exposure to MPs and Y. ruckeri. Results are illustrated as mean \pm SD. Significant differences between groups were identified by alphabetical characters $(P<0.05)$. 

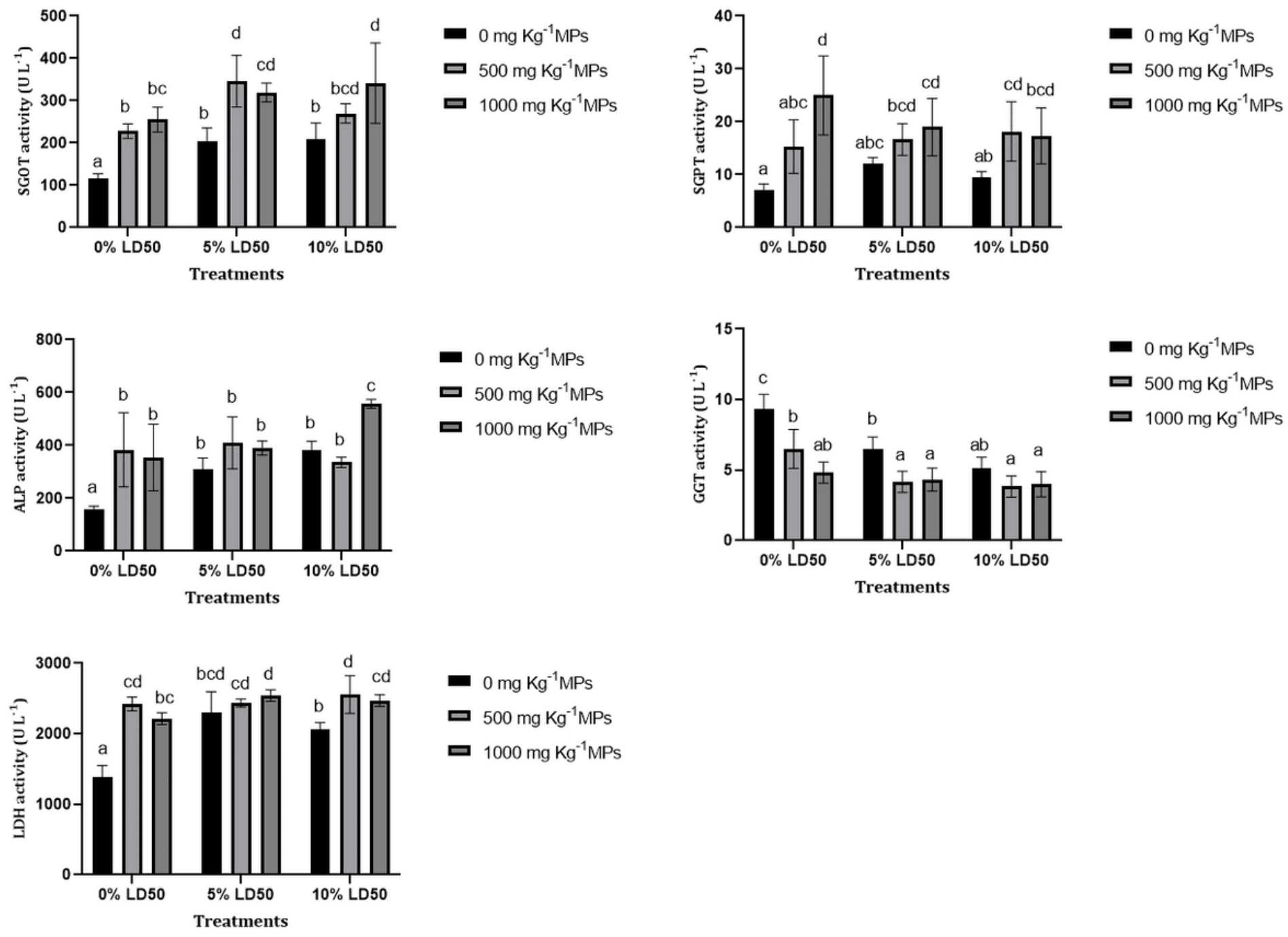

Figure 3

Changes of SGOT, SGPT, ALP, LDH, and GGT activities in the blood of rainbow trout after exposure to MPs and Y. ruckeri. Results are illustrated as mean \pm SD. Significant differences between groups were identified by alphabetical characters $(P$ $<0.05)$. 

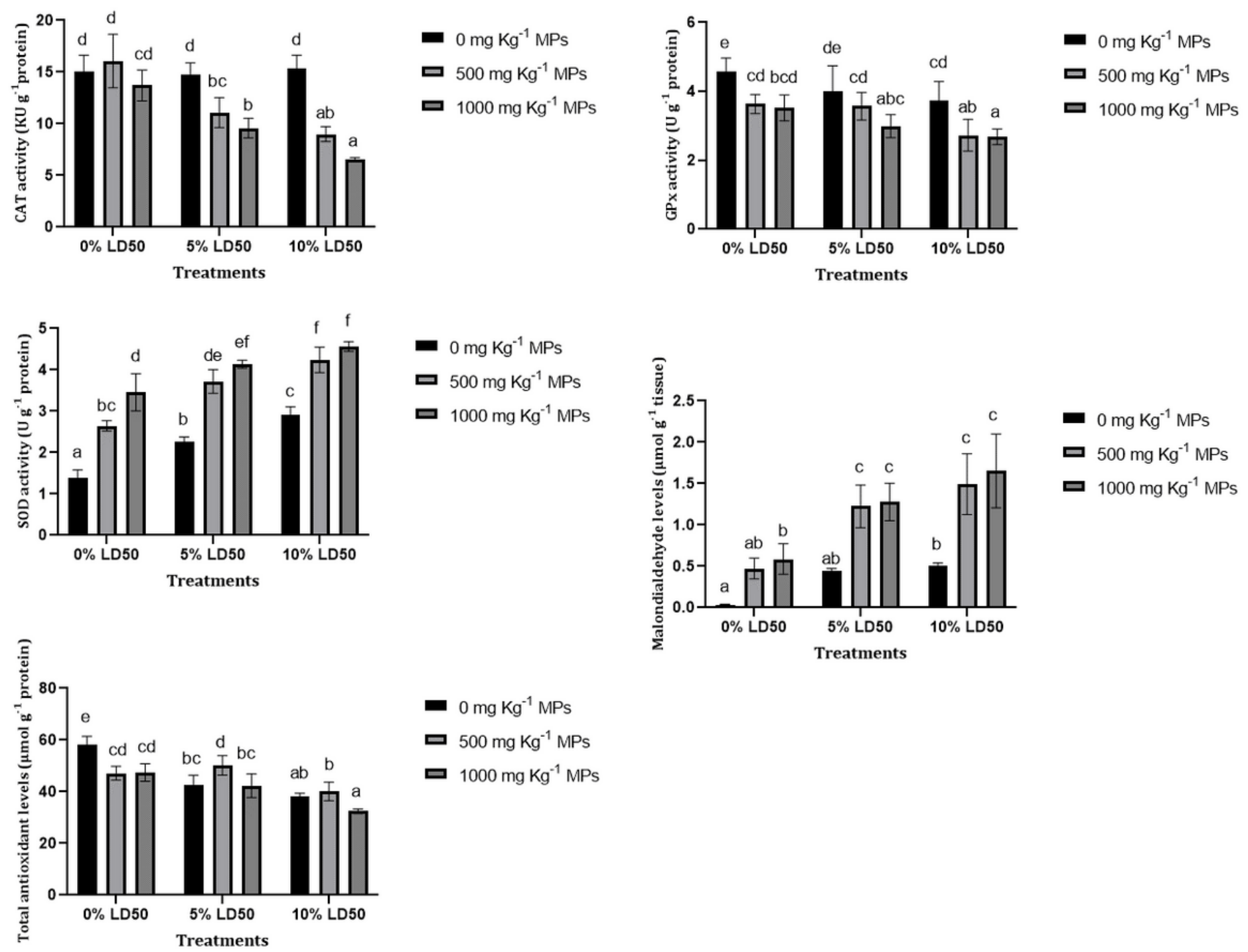

Figure 4

Changes of CAT, GPx, SOD activities, and MDA and total antioxidant levels in the hepatocyte of rainbow trout after exposure to MPs and Y. ruckeri. Results are illustrated as mean \pm SD. Significant differences between groups were identified by alphabetical characters $(P<0.05)$. 